\title{
Distribution of interleukin-1 receptor complex at the synaptic membrane driven by interleukin- $1 \beta$ and NMDA stimulation
}

\author{
Fabrizio Gardoni, Mariaserena Boraso, Elisa Zianni, Emanuela Corsini, Corrado L Galli, Flaminio Cattabeni, \\ Marina Marinovich, Monica Di Luca, Barbara Viviani*
}

\begin{abstract}
Interleukin-1 $\beta$ (IL-1 $\beta)$ is a pro-inflammatory cytokine that contributes to neuronal injury in various degenerative diseases, and is therefore a potential therapeutic target. It exerts its biological effect by activating the interleukin-1 receptor type I (IL-1RI) and recruiting a signalling core complex consisting of the myeloid differentiation primary response protein 88 (MyD88) and the IL-1R accessory protein (IL-1RAcP). This pathway has been clearly described in the peripheral immune system, but only scattered information is available concerning the molecular composition and distribution of its members in neuronal cells. The findings of this study show that IL-1RI and its accessory proteins MyD88 and IL-1RAcP are differently distributed in the hippocampus and in the subcellular compartments of primary hippocampal neurons. In particular, only IL-1RI is enriched at synaptic sites, where it colocalises with, and binds to the GluN2B subunit of NMDA receptors. Furthermore, treatment with NMDA increases IL-1RI interaction with NMDA receptors, as well as the surface expression and localization of IL-1RI at synaptic membranes. IL-1 $\beta$ also increases IL-1RI levels at synaptic sites, without affecting the total amount of the receptor in the plasma membrane. Our results reveal for the first time the existence of a dynamic and functional interaction between NMDA receptor and IL-1RI systems that could provide a molecular basis for IL-1 $\beta$ as a neuromodulator in physiological and pathological events relying on NMDA receptor activation.
\end{abstract}

\section{Findings}

Interleukin-1 $(\mathrm{IL}-1 \beta)$ is a pro-inflammatory cytokine that is involved in the pathogenesis of a number of neurological disorders, possibly as a modulator of glutamatergic response [1]. This suggestion arises from the observation that IL- $1 \beta$ is often over-produced in injured tissues in which there are high levels of glutamate [2-4], and this over-production has been related to the exacerbation of glutamate-driven pathological conditions [4-6]. Various mechanisms have been identified that may explain the convergence between the IL- $1 \beta$ and glutamatergic systems [1], including hyperactivation of the NMDA receptor (NMDAR). IL-1 $\beta$ increases the activity of hippocampal neuronal NMDARs by phosphorylating the GluN2B subunit and thus enhancing NMDAinduced neuronal death [7]. The same mechanism is

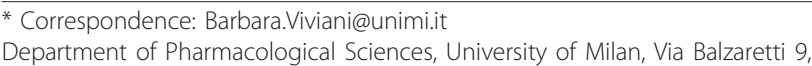

* Correspondence: Barbara.Viviani@unimi.it
Department of Pharmacological Sciences, University of Milan, Via Balzaretti 9, 20133 Milan, Italy
} 20133 Milan, taly

recruited in neurons as a consequence of the IL-1 $\beta$ released from glia by the HIV-virus glycoprotein gp 120 [8], and underlies the pro-convulsive effect of IL-1 $\beta$ [9]. Whatever mechanism may be recruited by IL- $1 \beta$, the involvement of IL-1RI is suggested by the uncontested neuroprotective effect of the IL-1 receptor antagonist (IL-1ra) $[4,10]$.

The binding of IL- $1 \beta$ to IL-1RI in the immune system leads to its association with the IL-1R accessory protein (IL-1RAcP) [11] and the myeloid differentiation primary response protein 88 (MyD88) [12] to form the core of the IL-1 $\beta / \mathrm{IL}-1 \mathrm{R}$ signalling complex. However, little information is currently available concerning the molecular composition of the members of the IL-1R complex, or their subcellular distribution and functional cross-talk with NMDARs in neuronal cells [13-15]. This is a major gap in our knowledge of the pathological mechanisms involving IL-1 $1 \beta / \mathrm{IL}-1 \mathrm{RI}$ in neurons that may 
be relevant to therapeutic interventions in the central nervous system (CNS).

The distribution of IL-1RI, IL-1RAcP and MyD88, together with the pre- and post-synaptic markers synaptophysin and PSD-95, was investigated in different subcellular compartments purified from adult rat hippocampi by means of western blotting [16], and by means of confocal microscopy of primary hippocampal neurons.
Subcellular fractionation showed that IL-1RI, MyD88 and IL-1RAcP were present in all of the tested fractions but, although IL-1RI and MyD88 were particularly enriched in the postsynaptic density (PSD) fraction (Figure 1A, left panel), together with PSD-95 and the GluN1 subunit of the NMDA receptor (Figure 1A, right panel), only traces of IL-1RAcP were present in the postsynaptic Triton-insoluble fraction (TIF) and PSD (Figure 1A, left panel). Confocal imaging showed that
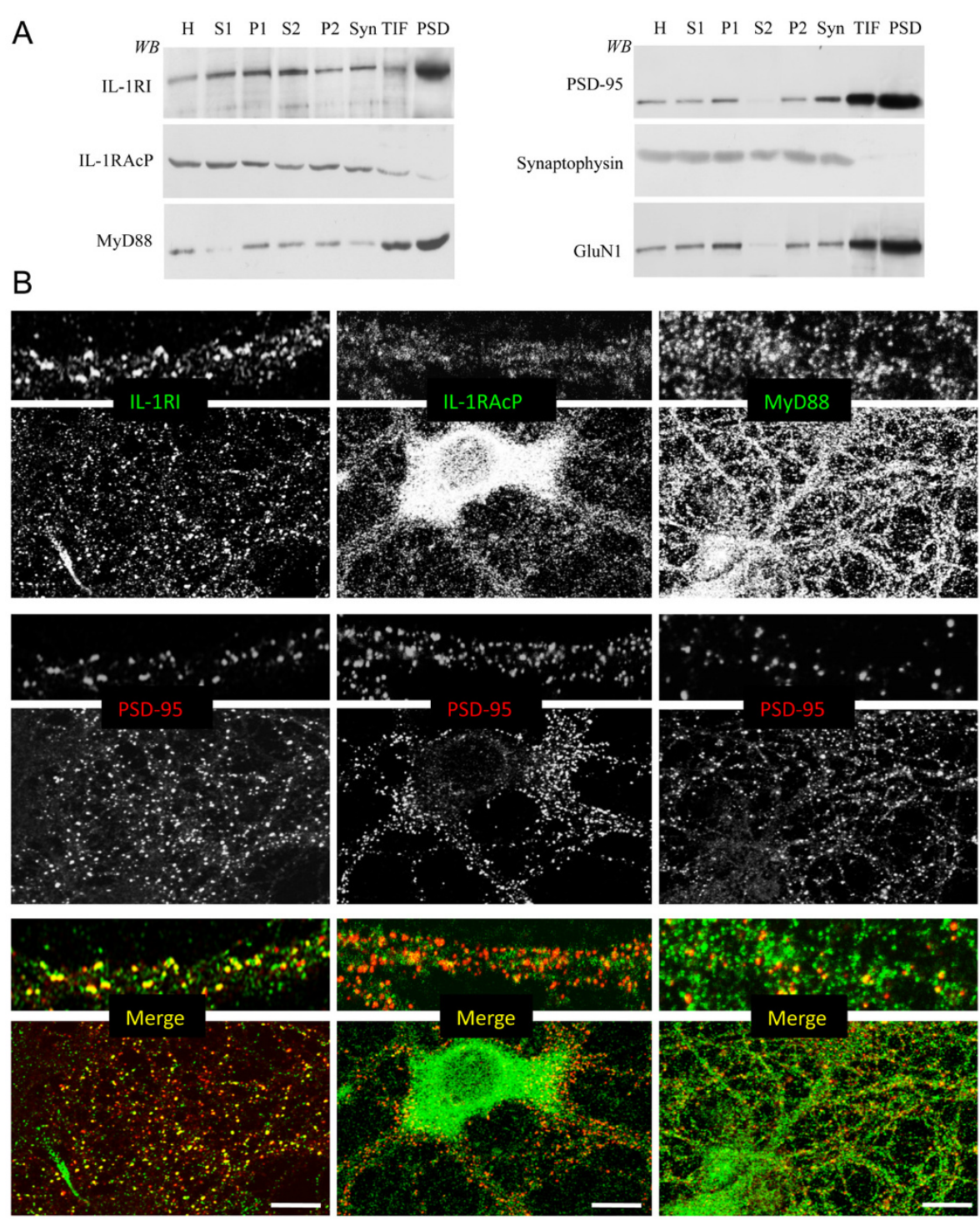

Figure 1 Characterisation of IL-1RI, IL-1RAcP and MyD88 subcellular distributions in rat hippocampi and primary hippocampal neurons. A: IL-1RI, IL-1RACP and MyD88, together with markers of the pre-synaptic compartment (synaptophysin) and post-synaptic side (PSD95, GluN1) were analysed in various rat hippocampus subcellular compartments by means of western blot. $\mathrm{H}=$ homogenate; $\mathrm{S} 1=$ low-speed supernatant; P1 = nuclei-associated membranes; S2 = high-speed supernatant; P2 = crude membrane fraction; Syn = synaptosomes; TIF = Tritoninsoluble postsynaptic fraction; PSD = post-synaptic density. B: DIV14 hippocampal neurons were immunolabelled for IL-1RI, IL-1RAcP and MyD88 (upper panels), and PSD-95 as a post-synaptic marker (middle panels). The bottom panels show the merged images. Scale bar: $10 \mu \mathrm{M}$. Highmagnification images are shown at the top of each panel. The antibody specific for IL-1RI was from Santa Cruz Biotechnology, Inc (Santa Cruz, CA) (M20) and its specificity has been tested by pre-absorption with the blocking peptide (data not shown). 


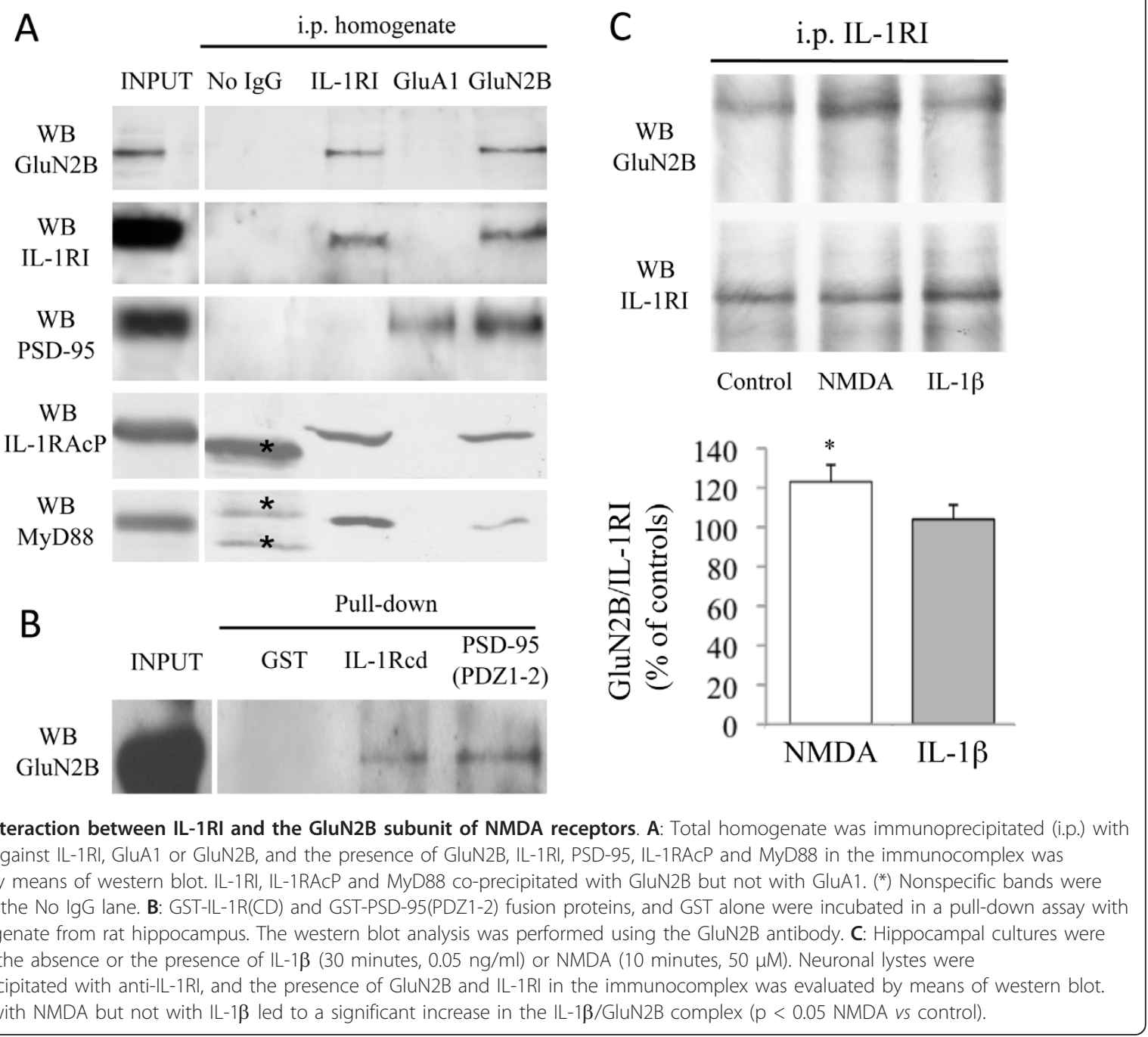

IL-1RI is distributed along dendrites and enriched in the post-synaptic compartment, as shown by the high degree of co-localisation with PSD-95 (34.3\% $\pm 3.7 \%$; Figure 1B, left panels). MyD88 was uniformly distributed along the neurons and moderately co-localised with PSD-95 (15.6\% $\pm 2.8 \%$; Figure $1 \mathrm{~B}$, right panels). IL1 RAcP labelling was intense and diffuse in the somatic cytoplasm of cultured neurons, and low and diffuse along the dendrites, and hardly co-localised with PSD$95(4.1 \% \pm 1.9 \%$; Figure $1 \mathrm{~B}$, central panels). Overall, these data suggest that there is a different subcellular distribution of the members of the IL-1R complex protein in neurons, with IL-1RI (and, to a lesser extent, MyD88) being enriched at the post-synaptic sites.

Co-immunoprecipitation experiments involving the components of the IL-1R complex and the AMPA and NMDA receptor subunits were performed to assess the localisation and interactions of IL-1RI within distinct subdomains of the PSD structure [17]. Protein homogenates $(200 \mu \mathrm{g})$ from rat hippocampi were immunoprecipitated [18] with antibodies specific for IL-1RI, for the GluA1 subunit of AMPA receptors, or for the GluN2B subunit of the NMDA receptor. Each sample was then evaluated for the presence of: i) IL-1RI, IL1RAcP and MyD88; ii) the GluN2B subunit: and iii) PSD-95. Figure 2A shows that, in hippocampal lysates, IL-1RI not only co-precipitated with IL-1RAcP and MyD88, but also with GluN2B; the absence of any PSD-95 signal in the IL-1RI co-immunoprecipitates excludes the possibility that, under our experimental conditions, the co-precipitation of GluN2B reflected nonspecific immunoprecipitation of insoluble synaptic proteins. In line with this, GluN2B co-precipitated with IL-1RI, thus confirming the association between 
these components (Figure 2A, right lane). Finally, none of the members of the IL-1R complex was detectable in the immunocomplex of the GluA1 subunit of AMPA receptors, which suggests a specific interaction between the GluN2B subunit of the NMDA receptor and IL-1R complexes (Figure 2A).

The association between IL-1RI and GluN2B was confirmed by a pull-down assay based on a fusion protein of the cytoplasmic domain of IL-1RI with GST
(GST-IL-1Rcd) (Figure 2B), which contained the C-terminal 369-569 aa domain of IL-1RI. As a positive control, we used a GST-PSD-95 (PDZ1-2) fusion protein that has been previously shown to bind the GluN2B subunit of NMDA receptors [18]. Lysates from rat hippocampal neurons were applied to affinity beads and extensively washed, after which the bound material was resolved by SDS-PAGE and underwent immunoblotting analysis using an antibody raised

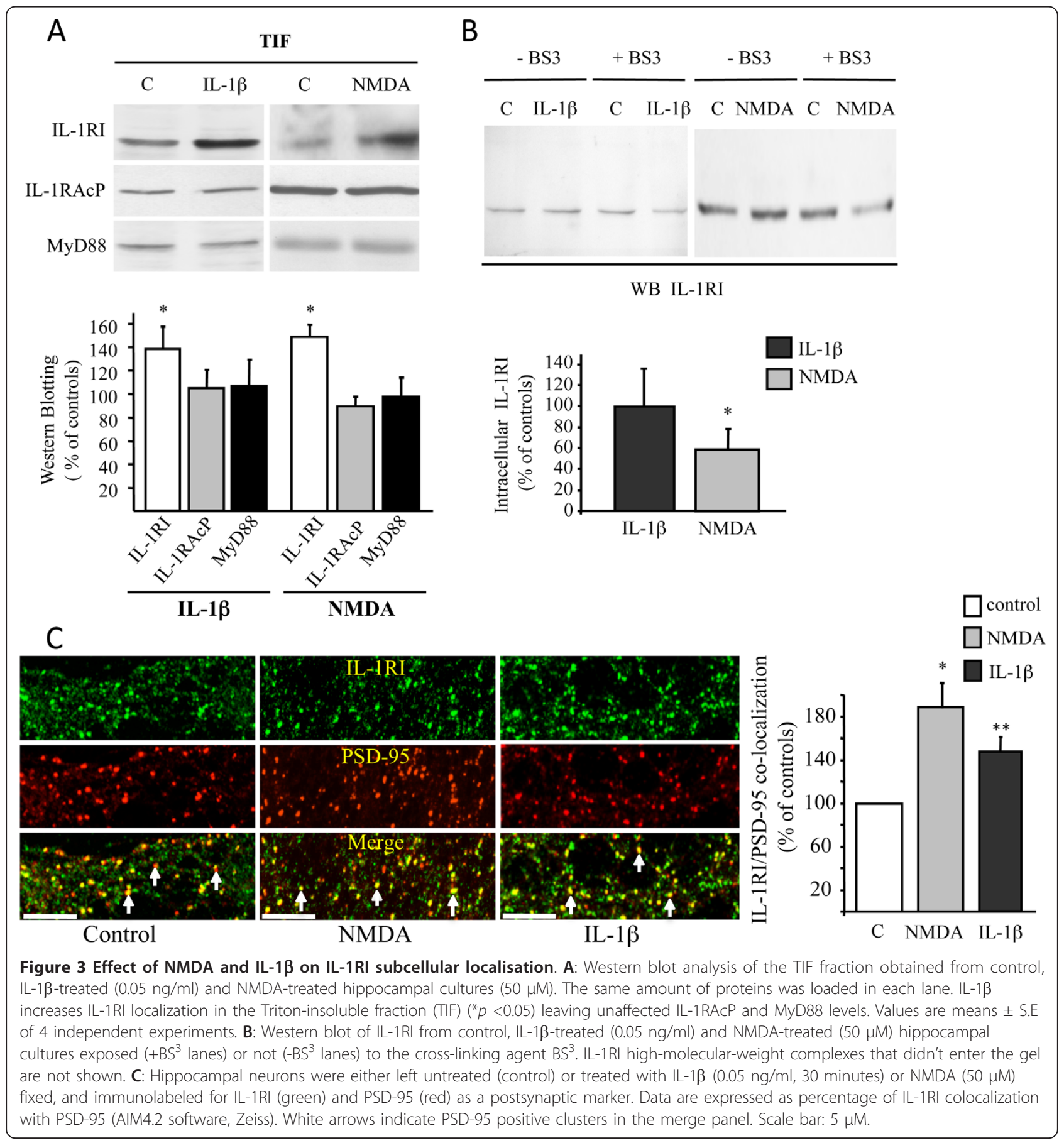


against GluN2B. Figure 2B shows that both IL-1Rcd and PSD-95 (PDZ1-2) associated with the GluN2B subunit, thus confirming a specific association between IL-1RI and GluN2B.

As it is well known that the synaptic localisation of receptors and ion channels, together with their proteinprotein interactions, are modulated in response to various stimuli, and that they undergo dynamic changes under physiological and pathological conditions $[19,20]$, we investigated the possibility that IL-1RI distribution and interaction with GluN2B may be dynamically modulated. Given the relationship between the IL-1 $\beta$ receptor complex and NMDAR, we treated primary hippocampal neurons with IL- $1 \beta, 0.05 \mathrm{ng} / \mathrm{ml}$, for $30 \mathrm{~min}$ (a concentration that also enhances NMDAR activity) [7] or NMDA, $50 \mu \mathrm{M}$, in ACSF buffer [7]: the NMDA was applied to the neurons for $10 \mathrm{~min}$, after which the cells were washed and incubated for a further $20 \mathrm{~min}$ in ACSF buffer. We first tested whether IL1- $\beta$ and/or NMDA modulated the interaction between IL-1RI and the GluN2B subunit of the NMDA receptor (Figure 2C). IL-1RI was immunoprecipitated from total lysates of primary hippocampal neurons treated or not with NMDA, $50 \mu \mathrm{M}$, or IL-1, $0.05 \mathrm{ng} / \mathrm{ml}$, and assayed for GluN2B by means of western blotting (Figure $2 \mathrm{C}$ ). The results show that only NMDA significantly increased the interaction between IL-1RI and GluN2B (Figure 2C; $p<0.05$ NMDA vs control).

We then evaluated whether the members of the IL- $1 \beta$ receptor complex could be re-distributed in different neuronal compartments after stimulation with IL- $1 \beta$ or NMDA. Both NMDA and IL- $1 \beta$ significantly increased the amount of IL-1RI in the postsynaptic TIF fraction (Figure 3A; $\mathrm{p}<0.05$, IL-1 $\beta$ or NMDA vs control). The treatments did not affect the synaptic distribution of either IL-1RAcP or MyD88. These results were confirmed by confocal microscopy (Figure 3C), which showed an increase in the co-localisation of IL-1RI with PSD-95 as quantified in the graph (Figure 3C).

The increase in IL-1RI receptors at the postsynaptic site may be due to new synthesis and delivery of receptors from the endoplasmic reticulum, or to lateral diffusion from adjacent compartments $[19,21]$, and this was addressed by carrying out surface expression assays using the non-cleavable, membrane-impermeable crosslinking agent $\mathrm{BS}^{3}[22]$. Primary hippocampal neurons were treated with IL-1 $\beta, 0.05 \mathrm{ng} / \mathrm{ml}$, or NMDA, $50 \mu \mathrm{M}$, and then exposed to $\mathrm{BS}^{3}$, lysed and blotted for IL-1RI. The intracellular amount of IL-1RI was reduced by NMDA but not by IL-1 $1 \mathrm{p}<0.05$, NMDA vs control; Figure $3 \mathrm{~B}$ ). The reduction in intracellular IL-1RI after NMDA exposure, together with its increase in the synaptic fraction, suggests that NMDAR activation favours the membrane insertion of new IL-1RI.
Alternatively, the increase in IL-1RI in the synaptic membrane may be attributable to stabilisation of the complex with NMDAR (within the core of the PSD), which could prevent lateral movement and/or endocytosis. In either case, a new pool of receptors would be made available. On the contrary, IL- $1 \beta$ possibly enriches IL-1RI at post-synaptic sites, promoting its lateral translocation (i.e. membrane diffusion) from extra-synaptic sites; however, this probably does not occur within the core microdomain of the PSD, as suggested by the unchanged levels of IL-1RI associated with the NMDAR complex.

In conclusion, ours are the first findings showing a molecular interaction between IL-1RI and the GluN2B subunit of NMDAR, and suggest a new molecular mechanism by means of which IL- $1 \beta$ and NMDA may dynamically regulate IL-1RI at post-synaptic sites. Furthermore, NMDA-dependent activation increases the amount of IL-1RI inserted into the membrane capable of interacting with released IL- $1 \beta$. This suggests a new molecular mechanism by means of which IL-1 $\beta$ may contribute to excitotoxicity, thus opening up new possibilities for targeted inhibition strategies that can be used in IL- $1 \beta /$ glutamate-driven CNS diseases.

\section{Abbreviations}

IL-1 $\beta$ : interleukin-1 $\beta$; IL-1 ra: IL-1 receptor antagonist; IL-1RI: interleukin-1 receptor type I; IL-1RACP: IL-1R accessory protein; MyD88: myeloid differentiation primary response protein 88; NMDAR: NMDA receptor; PSD: postsynaptic density; TIF: Triton-insoluble postsynaptic fraction.

\section{Acknowledgements and funding}

The study was supported by Progetti di Ricerca Indipendente Regione Lombardia - Iris-Biorad to BV and by PRIN2008 to MDL. We would like to thank Dr. Polentarutti for kindly providing the IL-1RI cDNA.

\section{Authors' contributions}

$\mathrm{FG}, \mathrm{BV}, \mathrm{MDL}, \mathrm{MM}, \mathrm{EC}, \mathrm{FC}$, and $\mathrm{CLG}$ designed the study; FG, MB, EZ and BV performed it; $F G, B V$ and $E C$ contributed new reagents/analytical tools; $M B$ and $E Z$ analysed the data; and FG and BV wrote the paper. All authors have read and approved the final version of the manuscript.

\section{Competing interests}

The authors declare that they have no competing interests.

Received: 1 December 2010 Accepted: 11 February 2011

Published: 11 February 2011

\section{References}

1. Fogal B, Hewett SJ: Interleukin-1beta: a bridge between inflammation and excitotoxicity? J Neurochem 2008, 106:1-23.

2. Pearson VL, Rothwell NJ, Toulmond S: Excitotoxic brain damage in the rat induces interleukin-1beta protein in microglia and astrocytes: correlation with the progression of cell death. Glia 1999, 25:311-323.

3. Vezzani A, Conti M, De Luigi A, Ravizza T, Moneta D, Marchesi F, De Simoni MG: Interleukin-1 beta immunoreactivity and microglia are enhanced in the rat hippocampus by focal kainate application: functional evidence for enhancement of electrographic seizures. $J$ Neurosci 1999, 19:5054-5065.

4. Liu S, Xu GY, Johnson KM, Echetebu C, Ye ZS, Hulsebosch CE, McAdoo DJ: Regulation of interleukin-1beta by the interleukin-1 receptor antagonist 
in the glutamate-injured spinal cord: endogenous neuroprotection. Brain Res 2008, 1231:63-74.

5. Lawrence CB, Allan SM, Rothwell NJ: Interleukin-1beta and the interleukin1 receptor antagonist act in the striatum to modify excitotoxic brain damage in the rat. Eur J Neurosci 2008, 10:1188-95.

6. Boutin $H$, LeFeuvre RA, Horai R, Asano M, Iwakura Y, Rothwell NJ: Role of IL-1alpha and IL-1beta in ischemic brain damage. J Neurosci 2001, 21:5528-5534.

7. Viviani B, Bartesaghi S, Gardoni F, Vezzani A, Behrens MM, Bartfai T, Binaglia M, Corsini E, Di Luca M, Galli CL, Marinovich M: Interleukin-1beta enhances NMDA receptor-mediated intracellular calcium increase through activation of the Src family of kinases. J Neurosci 2003, 23:8692-8700

8. Viviani B, Gardoni F, Bartesaghi S, Corsini E, Facchi A, Galli CL, Di Luca M, Marinovich M: IL-1beta released by gp120 drives neural death through tyrosine phosphorylation and trafficking of NMDA receptors. J Biol Chem 2006, 281:30212-30222.

9. Balosso S, Maroso M, Sanchez-Alavez M, Ravizza T, Frasca A, Bartfai T, Vezzani A: A novel non-transcriptional pathway mediates the proconvulsive effects of interleukin-1 beta. Brain 2008 131:3256-3265

10. Vezzani A, Moneta D, Conti M, Richichi C, Ravizza T, De Luigi A, De Simoni MG, Sperk G, Andell-Jonsson S, Lundkvist J, Iverfeldt K, Bartfai T: Powerful anticonvulsant action of IL-1 receptor antagonist on intracerebral injection and astrocytic overexpression in mice. Proc Natl Acad Sci USA 2000, 97:11534-9.

11. Korherr C, Hofmeister R, Wesche H, Falk W: A critical role for interleukin-1 receptor accessory protein in interleukin-1 signaling. Eur I Immunol 1997, 27:262-7.

12. Burns $K$, Martinon F, Esslinger C, Pahl H, Schneider P, Bodmer UL, Di Marco F, French L, Tschopp J: MyD88, an adapter protein involved in interleukin-1 signaling. J Biol Chem 1988, 273:12203-9.

13. Viviani B, Gardoni F, Marinovich M: Cytokines and neuronal ion channels in health and disease. Int Rev Neurobiol 2007, 82:247-263.

14. Brikos C, Wait $R$, Begum $S$, O'Neill $L A$, Saklatvala J: Mass spectrometric analysis of the endogenous IL-1RI signalling complex formed after IL-1 binding, identifies IL1RACP, MyD88 and IRAK-4 as the stable components. Mol Cell Proteomics 2007, 6:1551-1559.

15. Tsakiri N, Kimber I, Rothwell NJ, Pinteaux E: Differential effects of interleukin-1 alpha and beta on interleukin- 6 and chemokine synthesis in neurones. Mol Cell Neurosci 2008, 38:259-65.

16. Gardoni F, Caputi A, Cimino M, Pastorino L, Cattabeni F, Di Luca M: Calcium/calmodulin-dependent protein kinase II is associated with NR2A/B subunits of NMDA receptor in postsynaptic densities. Neurochem 1998, 71:1733-1741.

17. Chen X, Winters C, Azzam R, Li X, Galbraith JA, Leapman RD, Reese TS: Organization of the core structure of the postsynaptic density. Proc Natl Acad Sci USA 2008, 105:4453-4458.

18. Gardoni F, Schrama LH, Kamal A, Gispen WH, Cattabeni F, Di Luca M: Hippocampal synaptic plasticity involves competition between $\mathrm{Ca} 2$ +/calmodulin-dependent protein kinase II and postsynaptic density 95 for binding to the NR2A subunit of the NMDA receptor. J Neurosci 2001, 21:1501-1509

19. Newpher TM, Ehlers MD: Glutamate receptor dynamics in dendritic microdomains. Neuron 2008, 58:472-497.

20. Groc L, Bard L, Choquet D: Surface trafficking of N-methyl-D-aspartate receptors: physiological and pathological perspectives. Neuroscience 2009, 158:4-18.

21. Pérez-Otaño I, Ehlers MD: Learning from NMDA receptor trafficking: clues to the development and maturation of glutamatergic synapses. Neurosignals 2004, 13:175-189.

22. Mauceri D, Cattabeni F, Di Luca M, Gardoni F: Calcium/calmodulindependent protein kinase II phosphorylation drives synapse-associated protein 97 into spines. J Biol Chem 2004, 279:23813-23821.

doi:10.1186/1742-2094-8-14

Cite this article as: Gardoni et al:: Distribution of interleukin-1 receptor complex at the synaptic membrane driven by interleukin-1 $\beta$ and NMDA stimulation. Journal of Neuroinflammation 2011 8:14.

\section{Submit your next manuscript to BioMed Central and take full advantage of:}

- Convenient online submission

- Thorough peer review

- No space constraints or color figure charges

- Immediate publication on acceptance

- Inclusion in PubMed, CAS, Scopus and Google Scholar

- Research which is freely available for redistribution

Submit your manuscript at www.biomedcentral.com/submit
Ciomed Central 